\title{
Acute pulmonary vasodilatory properties of amlodipine in humans with pulmonary hypertension
}

\author{
Paul A Woodmansey, Lawrence O’Toole, Kevin S Channer, Alyn H Morice
}

\begin{abstract}
Objective-Calcium antagonists are the only oral vasodilators shown to influence mortality in primary pulmonary hypertension, but the high doses required are often poorly tolerated. Amlodipine is a novel, relatively well tolerated, calcium antagonist. It has not been previously tested in humans with pulmonary hypertension.
\end{abstract}

Design-Calcium antagonists are claimed to be of benefit in the $20-30 \%$ of patients who respond-that is, whose mean pulmonary artery pressure and pulmonary vascular resistance decrease by $20 \%$ after acute administration. Increasing oral doses of amlodipine (up to $40 \mathrm{mg}$ ) were given and haemodynamic measurements were obtained by the use of indwelling pulmonary artery catheters $12 \mathrm{~h}$ after each dose.

Setting-Large teaching hospital, primary referral centre.

Patients-Six patients (four women; age range 37-78 years) with pulmonary hypertension (one with primary pulmonary hypertension, five with thromboembolic disease.

Main outcome measures-Mean pulmonary artery pressure and pulmonary vascular resistance decreased by greater than $20 \%$ in two patients, mean pulmonary artery pressure decreased by greater than $20 \%$ in one patient with a pulmonary vascular resistance reduction of $19 \%$. Thus, two of six patients responded to amlodipine and one partially responded. Results-The whole group mean (SEM) pulmonary artery pressure decreased from $47 \cdot 7(4 \cdot 2)$ to $41 \cdot 7(4 \cdot 4) \mathrm{mm} \mathrm{Hg}$ and mean pulmonary vascular resistance from 8.6 $(2 \cdot 1)$ to $7 \cdot 1(1 \cdot 8)$ Wood units. Cardiac output rose by a mean (range) of $4 \%(-20.8$ to $+20 \cdot 8)$, heart rate by $8 \cdot 8 \%(-10$ to +33$)$, and systemic systolic blood pressure decreased by $12 \%(-29.2$ to $-5 \cdot 8)$ and diastolic blood pressure by $6.8 \%(-28 \cdot 2$ to $+20 \cdot 0)$. There were no symptoms of systemic hypotension.

Conclusion-These results show that oral amlodipine can produce acute pulmonary vasodilatation in patients with pulmonary hypertension. Further studies are required, but amlodipine may prove to be of value in the treatment of primary pulmonary hypertension.

(Heart 1996;75:171-173)
Keywords: amlodipine; calcium antagonist; pulmonary hypertension; acute pulmonary vasodilation

Primary pulmonary hypertension is a progressive and almost universally fatal condition, with a median survival time from diagnosis of 2-3 years. ${ }^{1-3}$ Calcium antagonists are the only oral vasodilators which are associated with a reduced mortality in this condition. ${ }^{4}$ Unfortunately, many patients with primary pulmonary hypertension are unable to tolerate treatment with a calcium antagonist because of the side effects associated with the high doses required. ${ }^{5}$

Amlodipine is a recently introduced dihydropyridine calcium antagonist with a slow onset of action and a half life of about $35-40 \mathrm{~h}$ in healthy humans. ${ }^{6}$ Because of its novel pharmacokinetic profile, amlodipine is generally well tolerated, ${ }^{78}$ and might therefore be a useful agent in the treatment of primary pulmonary hypertension. We have previously demonstrated the pulmonary vasodilating properties of amlodipine in studies of isolated pulmonary arteries, ${ }^{910}$ but do not know of any other reports of amlodipine as a pulmonary vasodilator in humans. This present study is an investigation of the effect of amlodipine in patients with pulmonary hypertension.

It has been suggested that calcium antagonists benefit only the $20-30 \%$ of patients with primary pulmonary hypertension who demonstrate pulmonary vasodilatation following acute administration, ${ }^{45}$ and in those who do not respond, their administration might be harmful. ${ }^{11}$ Response is defined as a $20 \%$ or greater reduction in pulmonary vascular resistance and mean pulmonary artery pressure. ${ }^{45}$ Thus, it has been recommended that treatment with a calcium antagonist is started only in patients who respond favourably as measured by invasive haemodynamic testing. ${ }^{245}$

\section{Patients and methods}

PATIENT POPULATION

Patients were considered eligible for this study if they had symptoms and signs of pulmonary vascular hypertension, with consistent findings on echocardiograms and electrocardiograms. Patients were excluded if they had evidence of secondary pulmonary hypertension. In particular, they were excluded if they had chronic chest disease of sufficient severity to produce pulmonary hypertension, or left heart pathology. Patients currently taking or intolerant of calcium antagonists were also excluded. 
Percentage change from baseline with maximum final dose of amlodipine

\begin{tabular}{|c|c|c|c|c|c|c|c|}
\hline Patient no & $\begin{array}{l}\text { Amlodipine } \\
\text { dose (mg) }\end{array}$ & $P A_{\text {mean }}$ & $\mathrm{CO}$ & $P V R$ & $H R$ & $S B P$ & $D B P$ \\
\hline $\begin{array}{l}1 \\
2 \\
3 \\
4 \\
5 \\
6 \\
\text { Mean }\end{array}$ & $\begin{array}{l}40 \\
40 \\
20 \\
20 \\
40 \\
40 \\
33\end{array}$ & $\begin{array}{r}+13.5 \\
-24.2 \\
-20.0 \\
-38.9 \\
+3.6 \\
-7.5 \\
-12.2\end{array}$ & $\begin{array}{r}0.0 \\
+20.8 \\
-20.8 \\
-0.5 \\
+17.6 \\
+6.8 \\
+4.0\end{array}$ & $\begin{array}{r}+19.2 \\
-18.6 \\
-25.9 \\
-67.9 \\
-9.6 \\
-26.4 \\
-23.1\end{array}$ & $\begin{array}{c}-10.0 \\
+2.3^{\star} \\
+7 \cdot 1 \\
+4.0 \\
+33.0 \\
+10.3 \\
+8.8\end{array}$ & $\begin{array}{r}-7 \cdot 2 \\
-29 \cdot 2 \\
-10 \cdot 0 \\
-5 \cdot 8 \\
-18 \cdot 1 \\
-15 \cdot 6 \\
-12.0\end{array}$ & $\begin{array}{r}-10.3 \\
-21.4 \\
+20.0 \\
-11.8 \\
-28.2 \\
+6.3 \\
-6.8\end{array}$ \\
\hline
\end{tabular}

SBP, systolic systemic blood pressure ( $\mathrm{mm} \mathrm{Hg}$ ); CO, cardiac output $(1 / \mathrm{min}) ; \mathrm{HR}$, heart rate (beats/min); $\mathrm{PA}$ mean mean pulmonary artery pressure (mm Hg); PVR, pulmonary vascular resistance (Wood units); DBP, diastolic systemic blood pressure (mm Hg). *Atrial fibrillation.

The role of thrombosis and thromboembolism in the aetiology of primary pulmonary hypertension remains uncertain, ${ }^{12}$ and patients with primary pulmonary hypertension have been shown to benefit from anticoagulation. ${ }^{4}$ Therefore, we investigated the haemodynamic response of patients with pulmonary hypertension associated with thromboembolic disease or due to primary pulmonary hypertension. Pulmonary thromboembolic disease was diagnosed on the basis of a history consistent with recurrent pulmonary emboli, and mismatching of ventilation and perfusion on pulmonary isotope scanning.

Ethical committee approval was given. Patients received verbal and written information regarding the procedure and thus gave fully informed consent.

\section{STUDY DESIGN}

Any concomitant vasodilating drug was withdrawn $72 \mathrm{~h}$ before the study. On the first study day each patient underwent right heart catheterisation. A 7 French gauge thermodilution Swan-Ganz flow directed catheter (Spectramed, British Oxygen Company, Swindon, UK) was inserted through the right internal jugular vein and remained in place throughout the study. Continuous pressure monitoring was achieved using a Supermon 7210 monitor (Kontron Instruments, Watford, UK). The measurements obtained were recorded as baseline data.

After oral dosing, peak plasma concentrations of amlodipine are achieved within $6-12 \mathrm{~h}$, and elimination half life is about 35-40 h. ${ }^{613}$ Therefore, a single oral dose of amlodipine was given daily at 2400 . Repeat measurements were made the following morning at the same time each day, by the same investigator for each patient, after at least $8 \mathrm{~h}$ of bed rest. Because the dose of amlodipine that might be appropriate in this setting is not known, $5 \mathrm{mg}$ was given on the evening of day 1 , followed by daily doses of 10,20 , and $40 \mathrm{mg}$ or until at least a $20 \%$ reduction in pulmonary vascular resistance and mean pulmonary artery pressure had been achieved, or the patient became intolerant.

\section{ANALYSIS}

Observed data are expressed as mean (SEM) and results derived as percentages of baseline are expressed as mean (range). In accordance with previous studies, response to treatment was defined as a $20 \%$ or greater reduction in pulmonary vascular resistance mean pulmonary artery pressure. ${ }^{45}$

\section{Results}

Six patients (four women; age range 37-78 years) were enrolled in this study. One patient had primary pulmonary hypertension and five had thromboembolic disease.

There were no important complications of the procedure. Internal jugular vein cannulation was not successful in patient no 4 and therefore the right subclavian approach was used.

The group mean (SEM) values were: initial systolic and diastolic pulmonary artery pressures were $84.3 \quad(7 \cdot 8) / 27 \cdot 3 \quad(3.6) \mathrm{mm} \mathrm{Hg}$ which decreased to $71 \cdot 6(9 \cdot 2) / 24 \cdot 7(2 \cdot 5) \mathrm{mm}$ $\mathrm{Hg}$ following amlodipine. Mean pulmonary artery pressure of $47.7(4.2) \mathrm{mm} \mathrm{Hg}$ also decreased to $41 \cdot 7(4 \cdot 4) \mathrm{mm} \mathrm{Hg}$. Pulmonary vascular resistance dropped following amlodipine from $8 \cdot 6(2 \cdot 1)$ to $7 \cdot 1(1 \cdot 8)$ Wood units.

The table gives the individual maximum dose of amlodipine with percentage change from baseline in haemodynamic variables.

Pulmonary arterial measurements remain reproducible after the first $24 \mathrm{~h}$ of right heart catheterisation. ${ }^{14}$ In this study we did not include a second control day because of the overall duration of the study. However, it would not be expected that the small initial dose ( $5 \mathrm{mg}$ ) of amlodipine would have an appreciable effect on pulmonary vascular resistance. There was no statistically significant change in pulmonary vascular resistance between baseline and day 1 (after $5 \mathrm{mg}$ amlodipine), consistent with minimal background fluctuations in pulmonary vascular resistance.

\section{SUMMARY OF RESULTS}

Amlodipine produced a reduction in mean pulmonary artery pressure of greater than $20 \%$ in three patients and in two of these a greater than $20 \%$ reduction in pulmonary vascular resistance was achieved. On average, cardiac output was little altered and although systemic heart rate generally rose and blood pressure decreased, these changes were well tolerated symptomatically.

\section{Discussion}

This is the first investigation of amlodipine in pulmonary hypertension in humans, and it has confirmed that acute pulmonary vasodilatation may be achieved with this agent. On the basis of previous reports, it would be expected that acute administration of a calcium antagonist would produce a pulmonary vasodilatory response in $20-30 \%$ of patients with primary pulmonary hypertension. ${ }^{512}$ The results of our 
study are compatible with this. Because the numbers are small, it is difficult to estimate the percentage of a larger series of patients who would be likely to respond to amlodipine.

In all except one patient, pulmonary embolic or thrombotic disease was considered likely. When thromboembolism seems to be the main factor underlying pulmonary hypertension, vasodilators might be less likely to produce acute pulmonary vasodilatation. The exact roles of active pulmonary vasoconstriction and thrombosis in primary pulmonary hypertension, however, are not clearly established. ${ }^{12}$ Anticoagulation results in a significant reduction in mortality in patients with primary pulmonary hypertension in whom there has been no evidence of pulmonary embolic disease. ${ }^{4}$ This suggests that vasoconstriction and thrombosis are important in the pathology of primary pulmonary hypertension and pulmonary thromboembolic disease. It may be that there is a spectrum of aetiology ranging from pure primary pulmonary hypertension to pure pulmonary thromboembolism.

Patient tolerability is a major problem in the treatment of primary pulmonary hypertension because of side effects due to the high dosage of calcium antagonists. ${ }^{45}$ Amlodipine was symptomatically well tolerated even at high doses in this small short-term study.

\section{Conclusions}

This study has shown that amlodipine is an effective pulmonary vasodilator in patients with pulmonary hypertension. Further studies are clearly required, but these results suggest that amlodipine might prove to be a useful agent in the treatment of primary pulmonary hypertension.

1 Wallcott G, Burchell HB, Brown AL Jr. Primary pulmonary hypertension. Am f Med 1970;49:70-9.

2 Hughes JD, Rubin LJ. Primary pulmonary hypertension. An analysis of 28 cases and a review of the literature. Medicine 1986;65:56-72.

3 Rich S, Dantzker DR, Ayres SM, et al. Primary pulmonary hypertension. A national prospective study. Ann Intern Med 1987;107:216-23.

4 Rich S, Kaufmann E, Levy P. The effect of high doses of calcium-channel blockers on survival in primary pulmonary hypertension. $N$ Engl F Med 1992;327:76-81.

5 Rich S, Brundage BH, Levy PS. The effect of vasodilator therapy on the clinical outcome of patients with primary pulmonary hypertension. Circulation 1985;71:1191-6.

6 Murdoch D, Heel RC. Amlodipine. A review of its pharmacodynamic and pharmacokinetic properties, and therapeutic use in cardiovascular disease. Drugs 1991;3: peutic use

7 Osterloh I. The safety of amlodipine. Am Heart 7 1989;118: 1114-20.

8 Neaton JD, Grimm RH, Prineas RJ, Stamler J, Grandits GA, Elmer PJ, et al. Treatment of mild hypertension GA, Elmer PJ, et al. Treatment
study. $¥ A M A$ 1993;270:713-24.

9 Woodmansey PA, Zhang F, Channer KS, Morice AH. The vasodilatory action of the calcium antagonist amlodipine on large and resistance pulmonary arteries from normoxic and chronically hypoxic rats. Clin Sci 1993;85:361-6.

10 Woodmansey PA, Zhang F, Channer KS, Morice AH. The effect of the calcium antagonist amlodipine on the two phases of hypoxic pulmonary vasoconstriction in rat large and small isolated pulmonary arteries. $\mathcal{f}$ Cardiovasc Pharmacol 1995;25:324-9.

11 Weir EK. Diagnosis and management of primary pulmonary hypertension. In: Wier EK, Reeves JT, eds. Pulmonary hypertension. New York: Futura Publishing Company, 1984:115-68.

12 Dantzker DR. Treating pulmonary hypertension. In: Weir EK, Archer SL, Reeves JT, eds. The diagnosis and treatment of pulmonary hypertension. New York: Futura ment of pulmonary hypertension.
Publishing Company, 1992:127-38.

13 Faulkner JK, McGibney D, Chasseaud LF, Perry JL, Taylor IW. The pharmacokinetics of amlodipine in healthy volunteers after single intravenous and oral doses and after 14 repeated oral doses given once daily. $B r \mathcal{F}$ and after 14 repeated oral doses

14 Packer M, Medina N, Yushak M. Haemodynamic changes mimicking a vasodilator drug response in the absence of drug therapy after right heart catheterization in patients with chronic heart failure. Circulation 1985;71:761-6. 